- Editorial Notes •

\title{
Preface to the Special Issue on Summer 2020: Record Rainfall in Asia - Mechanisms, Predictability and Impacts $*$
}

\author{
Robin T. CLARK ${ }^{1}$, Xiquan DONG ${ }^{2}$, Chang-Hoi HO${ }^{3}$, Jianhua $\mathrm{SUN}^{4}$, Huiling YUAN ${ }^{5}$, and Tetsuya TAKEMI \\ ${ }^{1}$ Met Office Hadley Centre, FitzRoy Road, Exeter EX1 3PB, UK \\ ${ }^{2}$ Department of Hydrology and Atmospheric Sciences, University of Arizona, Tucson, AZ 85721 0011, USA \\ ${ }^{3}$ School of Earth and Environmental Sciences, Seoul National University, Seoul 08826, Korea \\ ${ }^{4}$ Key Laboratory of Cloud-Precipitation Physics and Severe Storms (LACS), Institute of Atmospheric Physics, \\ Chinese Academy of Science, Beijing 100029, China \\ ${ }^{5}$ School of Atmospheric Sciences and Key Laboratory of Mesoscale Severe Weather/Ministry of Education, \\ Nanjing University, Nanjing 210023, China \\ ${ }^{6}$ Disaster Prevention Research Institute, Kyoto University, Uji 611-0011, Japan
}

\begin{abstract}
Citation: Clark, R. T., X. Q. Dong, C.-H. Ho, J. H. Sun, H. L. Yuan, and T. Takemi, 2021: Preface to the Special Issue on Summer 2020: Record Rainfall in Asia - Mechanisms, Predictability and Impacts. Adv. Atmos. Sci., 38(12), 1977-1979, https://doi.org/10.1007/s00376-021-1010-5.
\end{abstract}

Throughout vast areas of Asia, the summer of 2020 was extraordinarily wet. After an exceptionally wet May in Northeast India and Bangladesh, excessive rainfall hit at least 10 provinces in central and southern China in June and July, causing extensive flooding in many rural and urban locations. Long standing rainfall, lake and river level records were consequently broken in several parts of the region with the Yangtze-Huaihe river valleys, particularly badly impacted, with consequential economic losses. Floods and landslides also affected parts of Japan with at least one location in Kumamoto province even experiencing a record-breaking $1000 \mathrm{~mm}$ of rainfall in just 3 days in early July. The 2020 wet season in South Korea was also exceptionally long, lasting 54 days, compared to their more usual 32.

In the regions affected, the 2020 summer was, overall, the wettest since the notoriously wet summer of 1998, and in some locations the wettest for almost 60 years (Ding et al., 2021a). A striking difference, from 1998, however was the absence in 2020, of a classical, major El Niño event, often a key precursor of wet summers in the region. Considering the rainfall and its impacts, this special issue of AAS is therefore devoted to focusing almost exclusively on the 2020 summer with the aim of understanding what happened, its causes, predictability and potential reoccurrence in future decades.

A key aspect of the 2020 summer, reported in all of the papers in the issue, is the unprecedented strength and westward extension of the climatological anticyclone in the subtropical west Pacific. As Cui et al. (2021) shows, this had the effect of strengthening southwesterly flow carrying moisture towards the regions of heaviest rainfall. Unusually warm sea surface temperatures in the Indian Ocean appear to have been a key cause of the anticyclone's behaviour, demonstrated in the papers by Ding et al. (2021b), Fang et al. (2021), Liang et al. (2021), Pan et al. (2021) and Tang et al. (2021). Anomalous convection from the Indian Ocean helped to prolong the unusual behaviour of the Pacific anticyclone through a Matsuno-Gilllike teleconnection (Matsuno, 1966; Gill, 1980) and a long-lived phase of the Madden Julian Oscillation (Liang et al., 2021). Fang et al. (2021) and Pan et al. (2021) attribute the unusually warm Indian Ocean during 2020 to its long-term warming trend and interannual variability, which potentially could have repercussions in coming decades if the warming trend continues.

Although the summer wasn't preceded by a significant east Pacific El Niño event, a weak central Pacific warming did occur (Feng et al., 2021) which rapidly decayed during early 2020. Ding et al. (2021b) and Pan et al. (2021) both show how the rapid cooling and subsequent emergence of negative La Niña-like temperature anomalies in the central and eastern Pacific supported the anticyclone's development, in tandem with the influence of the anomalously warm Indian Ocean.

In addition to the effect of tropical circulation, cold advection by anomalous northeasterlies from Northeast Asia also

※ This paper is a contribution to the special issue on Summer 2020: Record Rainfall in Asia — Mechanisms, Predictability and Impacts. 
played a role (Pan et al., 2021). The location of the rainfall is also covered by Wang et al. (2021a) in a detailed analysis demonstrating how four particularly wet periods of the 2020 summer were also heavily influenced by factors outside of the region, such as in mid and high latitudes of Eurasia.

Other papers in the special issue take a closer look at the processes of the rainfall itself. Zhang et al. (2021), for example determines the principal sources of the moisture responsible and its transport towards the zones of heaviest rainfall, a theme which Volonté et al. (2021) also examine, in their reporting of the remarkably slow northward movement of the rainfall.

In addition to the seasonal mean anomalies, the rainfall along the mei-yu front also experienced a marked subseasonal fluctuation with multiple northward and southward swings (Ding et al., 2021a). Another striking aspect of the 2020 summer was the longitudinal eastward extension of the rainfall into the North Pacific, well beyond Japan. Narrow, ribbon-like atmospheric rivers of moisture appeared to have played a major part of this and are a focus of work by Wang et al. (2021b).

Two papers meanwhile, by Park et al. (2021) and Xia et al. (2021), focus on aspects of the rainfall's diurnal variability in Korea and China's Sichuan province respectively, with both reporting on the roles of moisture entrainment and convection which the large-scale circulation of 2020 appears to have enhanced. Further detailed insight into the mechanisms and role of topography resulting in the Sichuan rainfall is given by Hu et al. (2021).

Predictions of the summer on lead times of two weeks, a month and greater, are covered by several papers (Bett et al., 2021; Li et al., 2021; Liang et al., 2021). Forecast systems appear to have captured the observed large-scale patterns in the Indian and Pacific Oceans very well and successfully predicted the sign of the rainfall anomalies. However, as described in the above papers, the models significantly underpredicted the magnitude of the rainfall. Some of this could have resulted from internal variability, or from poor handling of mid-latitude processes from beyond the region, including, for example a Rossby train emanating from as far away as the Atlantic.

Finally, by using a circulation clustering approach, Clark et al. (2021) quantify the rarity of the circulation patterns of the 2020 summer and indicate how the rainfall in future summers with a similar circulation pattern to that of 2020 may change in a future world, warmed by increasing greenhouse gas concentrations.

Acknowledgements. Robin CLARK was supported by the UK-China Research \& Innovation Partnership Fund through the Met Office Climate Science for Service Partnership (CSSP) China as part of the Newton Fund. Chang-Hoi HO was supported by Korea Meteorological Administration Research and Development Program (Grant No. KMI2020-00610). Tetsuya TAKEMI was supported, on this topic, by the Environment Research and Technology Development Fund (ERTDF) JPMEERF20192005 of the Environmental Restoration and Conservation Agency (ERCA) of Japan.

\section{REFERENCES}

Bett, P. E., G. M. Martin, N. Dunstone, A. A. Scaife, H. E. Thornton, and C. F. Li, 2021: Seasonal rainfall forecasts for the Yangtze River basin in the extreme summer of 2020. Adv. Atmos. Sci., https://doi.org/10.1007/s00376-021-1087-x.

Clark, R. T., P. L. Wu, L. X. Zhang, and C. F. Li, 2021: The anomalous mei-yu rainfall of summer 2020 from a circulation clustering perspective: Current and possible future prevalence. Adv. Atmos. Sci., https://doi.org/10.1007/s00376-021-1086-y.

Cui, C. G., X. Q. Dong, B. Wang, and H. Yang, 2021: Phase two of the integrative monsoon frontal rainfall experiment (IMFRE-II) over the middle and lower reaches of the Yangtze River in 2020. Adv. Atmos. Sci., 38, 346-356, https://doi.org/10.1007/s00376020-0262-9.

Ding, L. D., T. Li, and Y. Sun, 2021a: Subseasonal and synoptic variabilities of precipitation over the Yangtze River Basin in summer 2020. Adv. Atmos. Sci., https://doi.org/10.1007/s00376-021-1133-8.

Ding, Y. H., Y. Y. Liu, and Z.-Z. Hu, 2021b: The record-breaking mei-yu in 2020 and associated atmospheric circulation and tropical SST anomalies. Adv. Atmos. Sci., https://doi.org/10.1007/s00376-021-0361-2.

Fang, C. X., Y. Liu, Q. F. Cai, and H. M. Song, 2021: Why does extreme rainfall occur in central China during the summer of 2020 after a weak El Niño? Adv. Atmos. Sci., https://doi.org/10.1007/s00376-021-1009-y.

Feng, L. C., F. Liu, R.-H. Zhang, X. Han, B. Yu, and C. Gao, 2021: On the second-year warming in late 2019 over the tropical Pacific and its triggering mechanism attributed to Indian Ocean effects. Adv. Atmos. Sci., https://doi.org/10.1007/s00376-021-1234-4.

Gill, A. E., 1980: Some simple solutions for heat-induced tropical circulation. Quart. J. Roy. Meteor. Soc., 106, 447-462, https://doi.org/10.1002/qj.49710644905.

Hu, X. L., W. H. Yuan, and R. C. Yu, 2021: The extraordinary rainfall over the Eastern Periphery of the Tibetan Plateau in August 2020. Adv. Atmos. Sci., https://doi.org/10.1007/s00376-021-1134-7.

Li, C. F., R. Y. Lu, N. Dunstone, A. A. Scaife, P. E. Bett, and F. Zheng, 2021: The seasonal prediction of the exceptional Yangtze River rainfall in Summer 2020. Adv. Atmos. Sci., https://doi.org/10.1007/s00376-021-1092-0.

Liang, P., Z.-Z. Hu, Y. H. Ding, and Q. W. Qian, 2021: The extreme mei-yu season in 2020: Role of the madden-Julian oscillation and the cooperative influence of the pacific and Indian Oceans. Adv. Atmos. Sci., https://doi.org/10.1007/s00376-021-1078-y.

Matsuno, T., 1966: Quasi-geostrophic motions in the equatorial area. J. Meteor. Soc. Japan, 44, 25-43, https://doi.org/10.2151/ jmsj1965.44.1_25.

Pan, X., T. Li, Y. Sun, and Z. W. Zhu, 2021: Cause of extreme heavy and persistent rainfall over Yangtze River in summer 2020. 
Atmos. Sci., https://doi.org/10.1007/s00376-021-0433-3.

Park, C.-K., M. Chang, C.-H. Ho, K.-J. Ha, J. Kim, and B.-J. Sohn, 2021: Two types of diurnal variations in heavy rainfall during July over Korea. Adv. Atmos. Sci., https://doi.org/10.1007/s00376-021-1178-8.

Tang, S. L., J.-J. Luo, J. Y. He, J. Y. Wu, Y. Zhou, and W. S. Ying, 2021: Toward understanding the extreme floods over Yangtze River Valley in June-July 2020: Role of tropical oceans. Adv. Atmos. Sci., https://doi.org/10.1007/s00376-021-1036-8.

Volonté, A., M. Muetzelfeldt, R. Schiemann, A. G. Turner, and N. Klingaman, 2021: Magnitude, scale, and dynamics of the 2020 meiyu rains and floods over China. Adv. Atmos. Sci., https://doi.org/10.1007/s00376-021-1085-z.

Wang, H. J., J. H. Sun, S. M. Fu, and Y. C. Zhang, 2021a: Typical circulation patterns and associated mechanisms for persistent heavy rainfall events over Yangtze-Huaihe River Valley during 1981-2020. Adv. Atmos. Sci., https://doi.org/10.1007/s00376-021-11948.

Wang, T., K. Wei, and J. Ma, 2021b: Atmospheric rivers and mei-yu rainfall in China: A case study of summer 2020. Adv. Atmos. Sci., https://doi.org/10.1007/s00376-021-1096-9.

Xia, R. D., Y. L. Luo, D. L. Zhang, M. X. Li, X. H. Bao, and J. S. Sun, 2021: On the diurnal cycle of heavy rainfall over the Sichuan basin during 10-18 August 2020. Adv. Atmos. Sci., https://doi.org/10.1007/s00376-021-1118-7.

Zhang, L. X., D. Zhao, T. J. Zhou, D. D. Peng, and C. Xiao, 2021: Moisture origins and transport processes for the 2020 Yangtze River Valley record-breaking mei-yu rainfall. Adv. Atmos. Sci., https://doi.org/10.1007/s00376-021-1097-8. 